\title{
O Processo da Morte e do Morrer: Uma Visão dos Acadêmicos de Enfermagem
}

\author{
Olguimar Pereira Ivo ${ }^{1}$; Karina Oliveira Pedroso ${ }^{2}$
}

\begin{abstract}
Resumo: Resumo: Os objetivos desse estudo foram relatar as reações e sentimentos despertados nos graduandos de enfermagem diante do processo da morte e do morrer e averiguar a relação feita pelo acadêmico de enfermagem quanto à adequação do conhecimento científico e o enfrentamento da morte. Trata-se de uma pesquisa descritiva e exploratória, de natureza qualitativa, realizada com acadêmicos do $9^{\circ}$ e $10^{\circ}$ semestre do curso de enfermagem de uma Faculdade particular de uma cidade do Sudoeste da Bahia. Os acadêmicos entrevistados conceituaram a morte como uma passagem da vida humana para a vida espiritual, ausência dos sinais vitais, um processo doloroso e natural. A morte está presente cotidianamente na vida dos acadêmicos de enfermagem participantes desta pesquisa. Foi possível identificar o despreparo deles perante o processo de morte e morrer, o que causa sofrimento e revela que os sentimentos despertados são sempre negativos, evidenciando despreparo para o enfrentando da morte.
\end{abstract}

Descritores: Morte e morrer; Enfermagem; Reações; Sentimentos.

\section{The Process of Death and Dying: A Vision of Nursing Students}

\begin{abstract}
The objectives of this study were reporting the reactions and feelings aroused in nursing graduates before the process of death and dying and ascertain the relations hipmade by the academic of nurses regarding the adequacy of scientific knowledge and the confrontation of death. This is a descriptive and exploratory research, qualitative, conducted with students from the 9th and 10th semester of the nursing course in a private college of a city of Bahia Southwest. Respondents academic conceptualized death as a passage of human life to the spiritual life, the absence of vital signs, a painful and natural process. Dea this present every day in the lives of nursing students participated in this research. It was possible to identify heun prepared ness of them to the death and dying process, which causes suffering and reveal sthata roused feelings are always negative, showing a lack of preparation for facing death.
\end{abstract}

Keywords: Death and dying; Nursing; Reactions; Feelings.

\section{Introdução}

A morte é um tema que pode ser visto como um aspecto biológico, social e cultural. Ao indagarmos o que é a morte, entendemos que há uma linguagem singular em sua definição. A ciência explica a morte na perspectiva biológica, ou seja, "a morte consiste, simplesmente, na paralisação total da máquina-corpo" (CAPRA, 1998, p. 138).

\footnotetext{
${ }^{1}$ Mestrado profissional com linha de pesquisa em Ética e Gestão, Faculdades EST - São Leopoldo - RS (2013). Especialização em Ativação de Processos de Mudanças da Formação Superior. Fundação Oswaldo Cruz, FIOCRUZ (2010).Especialização em Educação Profissional na Área de Saúde: Enfermagem Fundação Oswaldo Cruz, FIOCRUZ/RJ (2003). Possui graduação em Enfermagem pela Universidade Estadual do Sudoeste da Bahia (1994). Atualmente é coordenadora e docente do curso de enfermagem Enfermagem e docente do curso de Farmácia da Faculdade Independente do Nordeste FAINOR.

${ }^{2}$ Enfermeira. Graduada pela Faculdade Independentes do Nordeste e graduanda do curso de Pós-Graduação em Urgência e Emergência pela UNIGRAD. Email: karinaozahir@ hotmail.com
} 
Ainda que a morte faça parte do ciclo natural do ser humano e que para alguns seja vista tanto como o fim da vida quanto a possibilidade de renascimento, o encontro com o processo de morrer desperta nas pessoas, sentimentos que engloba as experiências vividas e, essas refletem a angústia existencial, despertando sentimentos nem sempre satisfatórios e conscientes (KÜBLER-ROSS, 2008).

O homem não sabe encarar abertamente seu próprio fim da vida, enfrentando durante o processo de morrer cinco estágios: a negação e isolamento, a raiva, a barganha, a depressão e a aceitação.

No primeiro estágio o paciente apresenta necessidade de isolar-se ou mesmo negar a doença, pois descobre que ela poderá colocar um fim à sua vida. O segundo estágio é o da raiva. Ela é sentida pelo doente exatamente pela impossibilidade de negar e se isolar por muito tempo. Nessa fase, surge também os sentimentos de inveja, revolta, e ressentimento. Constantemente é a equipe de enfermagem alvo da raiva dos pacientes (KÜBLER-ROSS, 2008).

O terceiro estágio é o da barganha. Depois de não poder mais negar a existência da morte e ter deixado de lado a raiva que não resolve, a pessoa recorre à Deus, normalmente em segredo, implorando um acordo em troca da vida na tentativa de adiar a morte. Assim, as barganhas assumem características de súplicas (KÜBLER-ROSS, 2008).

A depressão é o quarto estágio. Nele, quando o paciente toma consciência que não pode mais negar sua condição de doença, a morte se torna claramente sentida. Surge também o sentimento de perda, hora de encarar a triste realidade, quando começa a perceber que morrer é extremamente solitário. O quinto e último estágio é o de aceitação, que não nos remete ao sinônimo de passividade e de felicidade, pelo contrário, há alguns pacientes que lutam até o fim e se agarram à esperança de continuar a viver, não aceitando a morte evidente. Para outros pacientes, é a fuga de sentimentos, o momento de compreensão de sua vida, é como se a luta tivesse chegado ao fim e sabe que é chegado o seu momento (KÜBLER-ROSS, 2008).

A temática morte, conceito e significado, e o que ela representa socialmente, e o que significa sofreu diferentes mudanças ao longo da história. A representação da morte exerce interferência no modo como as pessoas se comportam, mudanças essas que também influenciam na atitude das pessoas (GUIMARÃES; CARNEIRO, 2012). 
Id on Line Revista Multidisciplinar e de Psicologia

Id on Line Multidisciplinary and Psycology Journal

O homem é o único animal que sabe antecipadamente da própria morte, ao contrário de outros animais sofre com o presente, passado e o futuro. Surgem questionamentos acerca do verdadeiro sentido de sua existência, porque a única certeza do homem, é de que um dia irá morrer.

Na Idade Média a morte era cercada de rituais públicos. Era comum ao doente despedirse da família e dos amigos, organizar tudo quanto fosse possível antes de a morte chegar. $\mathrm{Na}$ Idade Moderna, as atitudes do homem perante a morte modificam-se, a morte antes vista de forma natural, embasada em rituais ou como provação, agora passa a ser um evento vergonhoso, sinônimo de fracasso (SANTOS; HORMANEZ, 2013).

A temática morte incomoda e desafia a onipotência humana e profissional, as práticas cotidianas diante do sofrimento e da dor com enfoque na cura que nem sempre será bem sucedida, torna-se um grande desafio para os profissionais de saúde, significando sentimentos de fracasso e culpa (KOVÁCS, 2012).

O fato de o profissional de saúde focar toda sua atenção em equipamentos, verificar sinais vitais, poderá ser apenas um refúgio desesperado de rejeitar a morte iminente que faz lembrar a fragilidade e o medo de fracassar, assim como as limitações humanas, e até a própria mortalidade (KÜBLER-ROSS, 2008).

A equipe de saúde muitas vezes, influenciada pelo compromisso exclusivo com a vida e recuperação da saúde, aliada à luta contra a morte, enfatiza a cura. $\mathrm{O}$ trabalho da equipe enfatiza a cura. A equipe associa-se à eficácia tecnológica e faz da morte uma derrota profissional, um fracasso diante dos cuidados prestados (BORGES, 2011).

O profissional de enfermagem vivencia rotineiramente situações de morte e, cabe a este assistir o paciente durante o processo de morrer, mas essa não é uma tarefa fácil. Todos os profissionais da equipe se veem com necessidade de enfrentamento de reações diversas, como: tristeza, perda, impotência, culpa e medo. Muitas vezes, tais sentimentos estão associados ao medo do desconhecido, o que leva-nos à necessidade de refletirmos à respeito do que negamos. Outros profissionais conseguem encarar a morte como um evento natural, ou até mesmo usar mecanismos de defesa, permanecendo indiferentes talvez negando ou racionalizando a finitude da vida (LIMA; COSTA JÚNIOR, 2015). 
Durante a formação acadêmica do enfermeiro são dadas ênfases ao comprometimento com a vida, o que resulta em gratidão e recompensa pelo cuidado prestado. Nesse caso, não resta espaço para reflexão sobre a morte, fato esse que pode levar o graduando à sensação de incapacidade e despreparo (KOVÁCS, 2012).

No Brasil ainda são poucos os cursos de graduação de enfermagem que trabalham a temática morte como disciplina optativa da Matriz Curricular. Contudo, apesar dessa assertiva é importante afirmar que, durante a graduação pouco é discutido sobre a temática morte, o que não oferece embasamento para caracterizar o preparo do futuro profissional enfermeiro. $\mathrm{O}$ conceito que se tem de morte é algo singular, que dependerá também do contexto sociocultural, religiosidade, crença e as experiências vividas. A partir dessas questões é que se pode refletir a respeito das reações e sentimentos dos futuros enfermeiros no enfrentamento do processo da morte e do morrer (SANTOS, 2009).

Os graduandos de enfermagem durante toda sua formação acadêmica são conscientes do compromisso com o cuidar para promoção, recuperação e preservação da vida dos pacientes que estão sob seus cuidados. Assim, a morte passa a ser encarada como um imprevisto ou um fracasso em sua vida profissional. Essa lacuna nas matrizes curriculares durante a formação do discente de enfermagem, mostra a dificuldade para lidar com a temática morte-morrer.

Nesta perspectiva, o presente estudo tem por objetivo geral: Relatar as reações e sentimentos despertados nos graduandos de enfermagem diante do processo da morte e do morrer. Apresenta como objetivos específicos: Conhecer as experiências vivenciadas pelos acadêmicos de enfermagem diante do processo de morte e do morrer, e averiguar a relação feita pelo acadêmico de enfermagem sobre a adequação e aplicação do conhecimento científico para o enfrentamento da morte.

\section{Métodos}

Trata-se de uma pesquisa descritiva e exploratória, com abordagem qualitativa. A pesquisa descritiva tem por objetivo identificar, descrever e analisar as opiniões, atitudes e crenças de um determinado público. Esse tipo de pesquisa visa determinar a natureza da relação 
entre variáveis e não apenas sua existência. É exploratório, por estabelecer maior assimilação com o problema, tornando-o mais compreensível ou criar hipóteses. São utilizados os seguintes instrumentos: levantamento bibliográfico e entrevistas com pessoas que têm ou que já vivenciaram experiências com o problema pesquisado e analisar exemplos que instigue a compreensão (GIL, 2010).

A pesquisa qualitativa é traduzida por uma relação dinâmica entre o mundo real e o sujeito que não pode ser mensurável, pois são elementos indissociáveis que levam em consideração a subjetividade do sujeito, o que não pode ser traduzido em números, métodos e técnicas estatísticas. O ambiente natural é a fonte para a coleta de dados e o pesquisador o instrumento-chave (SILVA; MENEZES, 2005).

Na presente pesquisa, a abordagem qualitativa busca promover uma relação direta entre o sujeito e a realidade através da análise de atitudes e percepções dos acadêmicos de enfermagem acerca do assunto, contribuindo para a construção de novos conhecimentos.

O campo de estudo foi uma Faculdade privada situada em um município do interior da Bahia, localizada na região Sudoeste. A população participante do estudo foi composta de 30 acadêmicos de enfermagem dos turnos matutino e vespertino, devidamente matriculados no $9^{\circ}$ e $10^{\circ}$ semestre do curso, que já vivenciaram alguma experiência com o tema proposto para o estudo.

Os critérios de inclusão para participação da pesquisa foram: acadêmicos que aceitarem participar espontaneamente desse estudo e que já tenham vivências relacionadas ao objetivo do trabalho proposto, e os critérios de exclusão para participação da pesquisa: acadêmicos que não tiveram experiências com o processo de morte e morrer ou que não aceitaram participar da investigação.

A pesquisa foi constituída de duas etapas: Na primeira etapa foi aplicado um questionário semiestruturado adaptado, referenciado (BORGES, 2011), contendo 07 questões abertas. Em seguida foram selecionados de forma proposital alguns participantes para entrevista focalizada, realizadas individualmente pelo pesquisador em campo de estudo, gravado em aparelho eletrônico, com tempo de 40 minutos após permissão já concedida no Termo de Consentimento Livre Esclarecido. 
A entrevista é considerada a estratégia mais utilizada no processo de pesquisa de campo. É tomada como ampla comunicação verbal, restrita para coleta de informações pertinentes ao determinado objeto de pesquisa, abordado pelo entrevistador (MINAYO, 2014).

As falas dos participantes foram transcritas integralmente pelo pesquisador, analisadas de acordo análise de conteúdo conforme modelo de Bardin (2011) que prevê os seguintes estágios: pré-análise, a exploração do material e o tratamento dos resultados, que consiste na inferência e a interpretação, sendo classificado por categorias que auxiliam na compreensão do que está por trás dos discursos a fim de responder da melhor forma os questionamentos sobre o tema proposto. As falas serão armazenadas durante 05 anos, depois desse período serão descartadas pelo pesquisador.

A pesquisa foi aprovada pelo Comitê de Ética e Pesquisa da Faculdade (Protocolo n 56367516.0 .0000 .5578 ), no dia 12 de junho de 2016. Essa pesquisa respeitou os aspectos éticos de acordo com as normas regulamentadoras da Resolução 466/12 que trata de pesquisas envolvendo seres humanos, com objetivo de respeitar os sujeitos entrevistados sem expô-los.

A identidade dos participantes foi mantida em sigilo e os mesmos identificados por nome de flores: rosa, violeta, girassol, orquídea, etc. a fim de evitar qualquer situação de constrangimento no caso de publicação dos resultados da pesquisa. Além disso, os discentes do Curso de Enfermagem foram devidamente orientados quanto aos objetivos da pesquisa, ficando os mesmos livres para participarem ou não. Os que aceitaram, assinaram um Termo de Consentimento Livre e Esclarecido (TCLE).

\section{Resultados e Discussão}

Através da entrevista foi caracterizado o perfil dos acadêmicos de enfermagem com levantamento do gênero e faixa etária. A tabela 1, mostra que há uma predominância de participantes do gênero feminino $(93,3 \%)$ e quanto à idade, a faixa etária dos participantes varia de 18 a 48 anos. 
Id on Line Revista Multidisciplinar e de Psicologia

Id on Line Multidisciplinary and Psycology Journal

Tabela 1 - Levantamento dos participantes da pesquisa quanto ao gênero

\begin{tabular}{lcc}
\hline \multicolumn{1}{c}{ Gênero } & Número de participantes & \% \\
\hline Feminino & 28 & 93,3 \\
Masculino & 02 & 6,7 \\
\hline Total & 30 & 100 \\
\hline
\end{tabular}

Fonte: autor (2016)

De acordo com a análise de dados categorial temática, foi possível estabelecer 06 categorias para expor os resultados encontrados na pesquisa.

\section{Categoria 01: A concepção de morte}

A grande maioria dos acadêmicos de enfermagem considera a morte como uma passagem da vida humana para a vida espiritual, ausência dos sinais vitais, um processo doloroso e natural, o fechamento de um ciclo, conforme as falas citadas:

\footnotetext{
Rosa: "passagem de uma vida velha para a vida eterna".

Bromélia: "interrupção da vida, passagem de um plano material para um plano espiritual".

Tulipa: "término de uma longa jornada e início de uma plenitude".

Jasmim: "se refere ao aspecto físico, consiste na falência dos órgãos vitais e consequente ausência dos sinais vitais".

Lírio: "um processo natural, pelo qual todos passaremos".

Margarida: "algo que causa dor e desconforto".

Violeta: "um fechamento de um ciclo na terra entre as pessoas ocasionando tristeza, sentimento de perca e dor".
}

Para alguns a morte ainda representa concepções, como "fim do sofrimento", "passagem”, "paraíso", “início de uma nova vida”, “Deus”, “reencarnação”, representação das crenças e convicções espirituais do ser humano que busca uma possível explicação, um conceito para a morte. As palavras são insuficientes para descrever o processo de morte e morrer a partir do conhecimento disponível e complexidade do evento. É difícil definir a morte em um único conceito, cada pessoa tentará à sua maneira simbolizá-la (CANTÍDIO; VIEIRA; SENA, 2011).

Diante das revelações dos acadêmicos de enfermagem o estudo evidenciou que os entrevistados apresentaram dificuldades para conceituar a morte, relacionando o conceito às suas crenças pessoais, valores culturais e sociais. Outros ainda destacam o conceito de morte 
como algo natural. No entanto, percebe-se que essa definição se deve à influência do amadurecimento pessoal do indivíduo, pois a morte não é apenas um fato biológico, mas um processo que é construído socialmente. Todavia, as relações sociais e o momento vivenciado causa dor e desconforto. Deste modo, o grupo tem a percepção de que a morte, independente das causas e formas é algo inevitável, parte integrante de nossa existência.

\section{Categoria 02:Assistência de enfermagem prestada ao paciente no processo de morte}

Segundo relato dos acadêmicos, a assistência de enfermagem é realizada de forma humanizada, proporcionando uma assistência de qualidade além de oferecer amparo e conforto, tanto para o paciente diante da morte iminente como para os familiares.

\footnotetext{
Magnólia: "Assistência de qualidade, tentando oferecer uma assistência humanizada, física e espiritual".

Violeta: "além de prestar os cuidados necessários, transmitir ao paciente afetividade".

Iris azul: "Realizar cuidados paliativos, onde possamos dá um conforto para esse paciente".

Cravo: "no campo de estágio pude presenciar 03 óbitos, procuro seguir a rotina da unidade, sempre respeitando o paciente e a família".

Dália: "caracterizo como uma assistência de qualidade, baseada na integralidade, visando proporcionar conforto".

Girassol: "uma assistência com dignidade, afeto, procurando aliviar esse momento de sofrimento e dor".
}

O Profissional de Enfermagem deve exercer suas atividades com competência para promoção da saúde do ser humano na sua integralidade, cumprindo com os princípios da ética e da bioética. O Código de Ética da enfermagem na Seção I das relações com a pessoa, família e coletividade, Art. 19 - apresenta como responsabilidades e deveres: respeitar o pudor, a privacidade e a intimidade do ser humano, em todo seu ciclo vital, inclusive nas situações de morte e pós-morte (COREN-SC, 2010).

Os profissionais de enfermagem exercem papel fundamental no processo de cuidar, com visão ampla e humanizada, respeitando a ética profissional, atuando na promoção, prevenção e tratamento, oferecendo atendimento integral. 
Id on Line Revista Multidisciplinar e de Psicologia

Id on Line Multidisciplinary and Psycology Journal

\section{Categoria 03: A morte mais impactante}

As falas a seguir demonstram que as mortes inesperadas causaram mais impactos nos acadêmicos de enfermagem durante a realização de algum cuidado de enfermagem. A maioria das pessoas, assim como o profissional da enfermagem também se sensibiliza muito com o processo da morte de crianças e jovens.

\footnotetext{
Alecrim: “Aquela morte menos esperada. Morte de crianças, adolescentes...". Ipê: "A morte inesperada".

Lírio: "A morte por acidente e a morte súbita".

Bromélia: "A morte de um jovem independente da causa".

Cravo: "Jovem, criança que sofrem com o descaso da unidade e acabam falecendo".
}

Mesmo tendo consciência que a morte e o morrer são inerentes à condição humana e que faz parte do ciclo vital, quando esse ciclo não acontece de forma linear tende a ser muito mais doloroso. Não está no controle dos profissionais antever a morte, ela acontece de forma abrupta e coloca os profissionais de enfermagem diante da falta de controle da vida.

Quando presenciamos a morte de uma criança ou jovem, por se tratar do início da vida, é retirada a esperança e considerada como um fim prematuro da existência (LIMA; COSTA JÚNIOR, 2015), como pode ser observado na fala: Flor de lis: “[...] Uma criança ou um jovem que ainda teria muita coisa para viver e fazer durante a vida".

Sabemos que a morte é uma possibilidade presente e que pode acontecer em qualquer momento da vida, no entanto ela é mais tolerada e esperada quando se trata da finitude na velhice, porque não há interrupção precoce do ciclo vital.

O processo de morrer também é citado como um momento impactante para acadêmicos de enfermagem marcado de fortes emoções e dificuldades no enfrentamento.

Dália: "Mortes que causam sofrimento intenso para o paciente".

Alecrim: "A morte por doenças degenerativas e cancerígenas, pois é um processo demorado e doloroso".

Quando se prioriza a vida do paciente a todo custo, a certeza de uma doença que pode causar a morte, passa a ser percebida como um processo frustrante e desmotivador, o que pode acarretar para o profissional sentimento de impotência traduzido como extremamente doloroso (KOVÁCS, 2012). 
Id on Line Revista Multidisciplinar e de Psicologia

Id on Line Multidisciplinary and Psycology Journal

\section{Categoria 04: Sentimentos despertados frente ao processo de morte e morrer}

Diante das diversas formas dos acadêmicos de enfermagem conceituarem o processo de morte e morrer, diversos sentimentos emergem. As falas descritas revelam que os sentimentos despertados são sempre negativos: sofrimento, tristeza, impotência, insegurança, fracasso, angústia, dor e frieza.

\footnotetext{
Alecrim: "dor, tristeza e impotência".

Ipê: "Impotência, insegurança, tristeza. Você quer ajudar, no entanto não tem mais o que fazer".

Acácia: "Triste não gosto de assistir, fico muito mal".

Tulipa: "Tristeza, pois ninguém quer que um paciente morra por mais que seja esperado".

Jasmim: "pesar, sensação de impotência por não poder auxiliar de forma efetiva no processo e por não possuir em algumas situações força emocional para lidar com determinadas situações".

Lavanda: "Tristeza, por querer fazer algo e infelizmente não ter como".
}

Os dados encontrados nesse estudo são similares aos dados encontrados na literatura. A tristeza é um sentimento presente na vida do ser humano, em algum momento de sua vida o ser humano experimentará esse sentimento, no entanto, os profissionais de saúde são os mais vulneráveis a vivenciar isso diariamente (FREITAS, 2016).

O processo de morte e morrer no cotidiano dos profissionais de enfermagem estabelece os limites do saber e da ação, desencadeando muitas emoções negativas associadas à frustração que ameaça a assistência profissional (SANTOS; HORMANEZ, 2013). Desse modo, o momento que se depara com a iminência da finitude é traduzido como um terrível pesar. A dificuldade para encarar o processo de morte pode despertar necessidade de defesa e negação. Os acadêmicos de enfermagem, por não saberem lidar com os próprios sentimentos e não estarem preparados para enfrentar a situação, não conseguem visualizar outras estratégias para desvencilhar-se dessa situação, como evidencia: Flor de Lis: “desligo do paciente e da própria morte e consciente ou inconscientemente concentro minha atenção no meu trabalho".

De modo geral, estar diante da morte constitui uma tarefa difícil para os acadêmicos de enfermagem. Desde criança somos ensinados a não perder, além nos trazer a memória o término da vida de pessoas que amamos, ainda temos a sensação de não termos cumprido o principal objetivo profissional de salvar vidas. Como consequência, a morte do paciente é visa como fracasso, desencadeando reações e sentimentos negativos como: decepção, tristeza, angústia, 
Id on Line Revista Multidisciplinar e de Psicologia

Id on Line Multidisciplinary and Psycology Journal

pesar, culpa, dor, impotência, frieza, frustração e incerteza; todos esses sentimentos potencializam o medo da humanidade frente à situação de morte.

\section{Categoria 05: $O$ enfrentamento e $o$ apoio encontrado pelos acadêmicos de enfermagem diante do processo morte e morrer}

Diante das falas sobre o processo e enfrentamento da morte, percebe-se uma contradição entre o que os acadêmicos de enfermagem sentem e pensam sobre a morte e o morrer, e como eles agem diante da mesma.

\footnotetext{
Frésia: "Temos que enfrentar com firmeza, porém com sentimento: é uma vida!" Acácia: "tento ser o mais tranquila possível, mas não é fácil manter se forte perante a situação".

Girassol: "Ainda me abalo muito, mas tento ser forte e não fria, pois é necessário prestar a esse paciente a última assistência".

Rosa: "Tento não deixar com que os sentimentos se envolvam e penso que é uma etapa que todos passarão". Magnólia: "impotente".

Lírio: "Tentar ao máximo ficar firme e dá apoio psicológico aos familiares".
}

Os profissionais de saúde lançam mão de diversas alternativas para enfrentar a morte dos pacientes, mesmo que isso não evite ocorrência de prejuízos e danos emocionais no seu cotidiano de trabalho, mas a ocorrência desses eventos não quer dizer que eles não sofram com as perdas.

Percebe-se nas falas dos acadêmicos entrevistados a necessidade de desenvolver mecanismos de defesa para enfrentar a morte do paciente.

Os mecanismos de defesa utilizados pelos profissionais de saúde têm por finalidade reduzir qualquer situação de ameaça à integridade do Ego, e têm como base as angústias vivenciadas traduzidas por mecanismos de defesa. Nesse caso, ficam mais fortes, o que resulta numa tentativa de minimizar seu sofrimento (KUHN; LAZZARI; JUNG, 2011). Beladona: "Muitas vezes enfrento o processo com frieza, desde quando não tenha ligação direta com meu familiar".

Podemos concluir que os mecanismos de defesa são manobras psíquicas extremamente necessárias. Conforme relatos dos acadêmicos, essa busca é para manterem-se fortes, em 
Id on Line Revista Multidisciplinar e de Psicologia

Id on Line Multidisciplinary and Psycology Journal

equilíbrio, ao menos aparentemente. O resultado dessa procura é demonstrado pela tentativa de prestar a última assistência de enfermagem da forma adequada, segura e com a maior qualidade possível. É para isso que os acadêmicos de enfermagem são preparados durante toda sua formação, saber assumir atitudes de proteção para conseguir lidar com o processo de morte.

Para complementar a ideia inicial a respeito do enfrentamento do processo da morte e do morrer, faz-se o seguinte questionamento: Aonde os acadêmicos de enfermagem encontram apoio para atuarem diariamente com esse processo?

Uma grande parcela dos acadêmicos entrevistados relata que não recebem nenhum apoio para vivenciarem esse processo de morte e morrer. Girassol: "nesta área da saúde falta dos profissionais este apoio".

$\mathrm{O}$ enfermeiro exerce papel fundamental no processo do cuidar de forma ampla e humanizada, com ética profissional, atuando na promoção, prevenção e tratamento de forma integral do paciente. São profissionais de extrema importância, pois, além do conhecimento da realidade são articuladores das reais necessidades. No entanto, deve adquirir conhecimento científico, prático e psicológico para aturar diante do processo de cuidar (BASSO; WAINER, 2011).

Neste sentido, o profissional não está preparado psicologicamente para lidar com a morte, o que pode comprometer não só a assistência prestada, como trazer prejuízos à vida pessoal e afetiva. Durante sua formação, o enfermeiro precisa de apoio e suporte para conseguir organizar seus sentimentos e saber como agir diante do processo de morte e morrer. Nessa categoria podemos citar o despreparo de alguns processos na academia, quando emergem todos os sentimentos negativos diante da morte. O relato de Jasmim torna evidente a identificação dessa lacuna no conhecimento desses futuros profissionais.

\footnotetext{
Jasmim: "sinto falta de um apoio durante o curso de graduação, os mecanismos que desenvolvi foram durante as experiências do curso ou que adquiri durante a minha vida pessoal".
}

Os entrevistados que relataram que receberam algum tipo de apoio que vincularam às suas vivências espirituais e pessoais, citando a racionalização e a espiritualidade novamente como suporte para o enfrentamento do processo da morte e do morrer. 


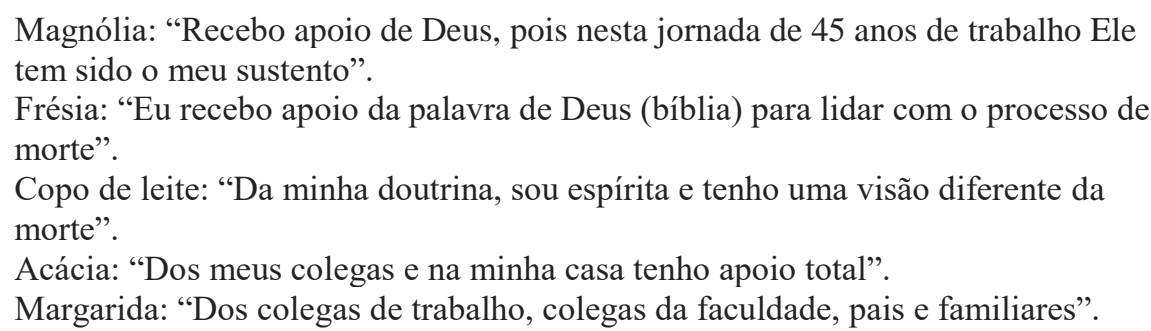

\section{Categoria 06: Preparo dos acadêmicos de enfermagem para lidar com a morte do paciente}

A morte estará sempre presente no cotidiano do enfermeiro. Desse modo, supõe-se que ele está preparado para vivenciar e entender esse processo como algo natural e inerente a todo o ser humano. No entanto, grande parte dos acadêmicos de enfermagem revela que não se sente preparado para enfrentar o processo da morte e morrer do seu paciente.

\footnotetext{
Frésia: “Ainda não me sinto preparada para lidar com tal situação, acho que precisamos ser mais preparados na faculdade e até mesmo ter cursos sobre o tema". Ipê: "ao longo da minha vida acadêmica eu fui me preparando para lidar com essa situação".

Magnólia: "é um momento muito difícil me sinto impotente, sempre achando que deveria fazer mais, o sofrimento dos familiares me deixa muito abalada".

Dália: "Apesar de saber que a morte é inevitável e todos nós passaremos por ela um dia, não me sinto preparada para lidar com ela”.
}

Diante dessas considerações, apesar de a morte ser um ponto crucial para a vida do futuro enfermeiro o desenvolvimento do tema "morte e morrer" por sua vez pouco foi debatido nos cursos de graduação em enfermagem. O intuito de formar profissionais reflexivos, críticos, capazes de atuar nos mais variados cenários que permeiam tanto a vida como a morte, deve ser também uma preocupação da academia (FREITAS, 2016).

$\mathrm{O}$ argumento da acadêmica entrevistada sustenta o fato das faculdades terem ementas das disciplinas focadas apenas no cuidar, na manutenção da vida e no conhecimento técnico. Hortênsia: "Tecnicamente sim, mas emocionalmente a morte sempre me deixa abalada".

Proporcionar a criação de espaços para discussões nas quais os sentimentos despertados diante da morte possam ser compartilhados é uma ferramenta de grande valor na graduação, de forma a minimizar as consequências no enfrentamento desse processo. Recomenda-se que 
Id on Line Revista Multidisciplinar e de Psicologia

Id on Line Multidisciplinary and Psycology Journal

algumas disciplinas enfatizem os sentimentos e reações geradas no acadêmico, não somente no que tange às aulas teóricas mediantes observação e discussão de casos, situações que auxiliem os profissionais de enfermagem a estarem aptos para lidar com qualquer tipo de situação, propiciando assim uma aproximação com pessoas nas diversas fases do desenvolvimento (AZEREDO; ROCHA; CARVALHO, 2011).

A morte não atinge os acadêmicos entrevistados do mesmo modo, a percepção e preparação para perda do paciente é determinada pela circunstância da morte. Contudo, a morte é um processo inevitável e faz parte da rotina hospitalar e, muitos profissionais de saúde não estão preparados para enfrentar a morte.

\footnotetext{
Jasmim: "me sinto preparada apenas em situações que ocorrem por um processo natural ou pela patologia".

Tulipa: "nem sempre, quando se estar com um paciente em estágio terminal é mais fácil, mas quando o paciente vai bem e de uma hora para outra morre, ai mexe com as estruturas".

Cravo: "Procuro aceitar aquela situação, pois muitas vezes é um alívio para o paciente e família. Existem casos onde o paciente sofre muito e muitas vezes a medicina não tem mais o que fazer".
}

Os indivíduos com atitudes naturais diante da vida e da morte estão seguros quanto aos seus sentimentos e demonstram maior capacidade para compreender e auxiliar às pessoas que estão diante do risco de morte iminente. Isso foi relatado com clareza por alguns acadêmicos entrevistados.

\footnotetext{
Iris azul: "Tenho comigo esse é um processo que passaremos em nossa vida, então para mim a morte nada mais que natural".

Girassol: "entendo que a morte é um descanso de todo sofrimento e que um dia todos nós passaremos por isso, então me sinto preparada para tal acontecimento". Margarida: "uma vez que entendo que a morte é uma passagem para vida, o meu psicológico dica mais tranquilo".

Alecrim: "a vida e a experiência acadêmica nos ensina a lidar com essa situação".
}

Ao fazermos uma retrospectiva dos momentos vivenciados pelos enfermeiros diante do processo da morte e do morrer, eles prestam assistência aos pacientes e esquecem que os familiares deles também precisam de cuidados específicos, visto que continuam vivos. $\mathrm{Na}$ maioria das vezes são "encaminhados" para outros profissionais como psicólogos e assistentes sociais, o que apenas confirma que esta não é a função do enfermeiro, evidenciado que não se sentem e não foram preparados para lidar com esse tipo de evento. Dessa forma, talvez nunca 
se sintam preparados, pois deixam passar a oportunidade de reflexão, discussão e amadurecimento para o enfrentamento do processo de morte (MARINHO, 2009). Como ressalta Amarilis: “Acho que ninguém está preparado, por ser um momento muito delicado $[\ldots] "$

\section{Considerações Finais}

A morte é um uma situação inevitável e difícil de ser vivenciada. Esse processo está presente cotidianamente na vida dos acadêmicos de enfermagem que participaram desse estudo. Os graduandos entrevistados revelaram que vivenciaram sentimentos, percepções, reações e enfrentamentos diversos diante do processo de morte e morrer, relacionando o conceito de morte dentro do aspecto, biológico, social e cultural.

Durante a realização da pesquisa foi possível identificar o despreparo dos acadêmicos de enfermagem para lidar com o processo de morte e morrer. Foi demonstrado por eles que o acompanhamento do processo de morte causa sofrimento e reflete sentimentos negativos como: tristeza, impotência, fracasso, angústia, dor e frieza. Esses sentimentos se tornam mais evidentes à medida que o acadêmico aproxima do término da graduação, pois durante sua formação é enfatizado que uma das atribuições do profissional da saúde é salvar vidas, mas é preciso enfatizar que a morte faz parte do ciclo vital.

Entretanto, não se deve colocar toda responsabilidade do despreparo dos futuros enfermeiros diante da morte na forma como a graduação foi desenvolvida. A compreensão de que a morte é também repensada a partir das vivências familiares, espirituais e emocionais de cada indivíduo, e demonstra que é um importante tema para futuras discussões. No entanto, é imprescindível que a contribuição do componente curricular do curso de enfermagem relate o processo de morte e morrer de forma mais detalhada. Isso deve significar a promoção e formação de profissionais preparados para refletir a respeito dos significados reais da vida e da morte. 
Id on Line Revista Multidisciplinar e de Psicologia

Id on Line Multidisciplinary and Psycology Journal

\section{Referências}

BARDIN, L. Análise de conteúdo. 3. reimp. Lisboa: Ed. 70, 2011.

BASSO, L. A.; WAINER, R. Luto e perdas repentinas: contribuições da terapia cognitivacomportamental. Revista Brasileira de Terapias Cognitivas, v. 7, n. 1, p. 35-43, 2011.

AZEREDO, N. S. G.; ROCHA, C. F.; CARVALHO, P. R. A. O enfrentamento da morte e do morrer na formação de acadêmicos de Medicina. Rev Bras Educ Med, v. 35, n. 1, p. 37-43, 2011.

BORGES, T. R. C. O enfrentamento da equipe de enfermagem no processo de morte e morrer do paciente. 50p. 2011. Monografia (Especialização em Assistência de Enfermagem em Urgência e Emergência) - Universidade do Extremo Sul Catarinense (UNESC), 2011.

CANTÍDIO, F. S.; VIEIRA, M. A.; SENA, R. R. de. Significado da morte e de morrer para os alunos de enfermagem. Invest Educ Enferm, v. 29, n. 3, p. 407-18, 2011.

CAPRA, F. O ponto de mutação. São Paulo: Cultrix, 1998.

CONSELHO REGIONAL DE ENFERMAGEM (COREN-SC). Consolidação da legislação $e$ ética profissional. Florianópolis: COREN-SC, 2010. 136 p.

FREITAS, T. L. de et al. O olhar da enfermagem diante do processo de morte e morrer de pacientes críticos: uma revisão integrativa. Enfermería Global, v. 15, n. 1, p. 322-360, 2016.

GIL, A. C. Como elaborar projetos de pesquisa.5. ed. São Paulo: Atlas, 2010.

GUIMARÃES, I. G.; CARNEIRO, M. H. S. Envelhecimento e finitude-qual a representação da morte? Estud. Interdiscipl. Envelhec., Porto Alegre, v. 17, n. 1, p. 7-18, 2012.

KOVÁCS, M. J. Educação para a morte - temas e reflexões. 2. ed. São Paulo: Casa do Psicólogo, 2012.

KÜBLER - ROSS, E. Sobre a morte e o morrer. 8. ed. São Paulo: M. Fontes, 2008. 295 p.

KUHN, T.; LAZZARI, D. D.; JUNG, W. Vivências e sentimentos de profissionais de enfermagem nos cuidados ao paciente sem vida. Rev. Bras. Enferm, v. 64, n. 6, p. 1075-1081, 2011.

LIMA, R. dos S.; COSTA JÚNIOR, J. A. O processo de morte e morrer na visão do enfermeiro. Revista Ciência \& Saberes-Facema, v. 1, n. 1, p. 25-30, 2015. 
Id on Line Revista Multidisciplinar e de Psicologia

Id on Line Multidisciplinary and Psycology Journal

MARINHO, C. M. da S. Cuidar de pacientes em prolongamento artificial da vida: concepção das enfermeiras. 2009. 99f. Dissertação (Mestrado em Enfermagem) - Universidade Federal da Bahia, 2009.

MINAYO, M. C. de S. O desafio do conhecimento. Pesquisa qualitativa em saúde. São Paulo: Hucitec, 2014.

SANTOS, F. S. (Org.). A arte de morrer: visões plurais. 1. ed. São Paulo: Comenius, 2009.

SANTOS, M. A. dos. HORMANEZ, M. Atitude frente à morte em profissionais e estudantes de enfermagem: revisão da produção científica da última década. Revista Ciência \& Saúde Coletiva, v. 18, n. 9, p. 2757-2768, 2013.

SILVA, E. L.; MENEZES, E. M. Metodologia da pesquisa e elaboração de dissertação. 4. ed. Florianópolis: UFSC, 2005.

\section{Como citar este artigo (Formato ABNT):}

IVO, Olguimar P.; PEDROSO, Karina O. O Processo da Morte e do Morrer: uma Visão dos Acad emicos de Enfermagem. Id on Line Revista Multidisciplinar e de Psicologia, Fevereiro de 2017, vol.11, n.34, p. 271-280. ISSN: 1981-1179.

Recebido: 06.01.2017

Aceito: 27.02 .2017 